\title{
CELL AGGREGATION ENHANCES BONE FORMATION BY HUMAN MESENCHYMAL STROMAL CELLS
}

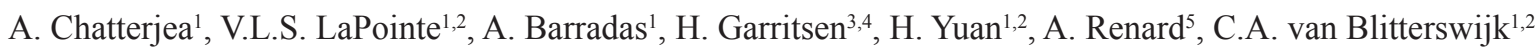 \\ and J. de Boer ${ }^{1,6 *}$ \\ ${ }^{1}$ Department of Tissue Regeneration, MIRA Institute for Biomedical Technology and Technical Medicine, \\ University of Twente, PO Box 217, 7500 AE Enschede, The Netherlands \\ ${ }^{2}$ Current Address: Department of Complex Tissue Regeneration, MERLN Institute for Technology-Inspired \\ Regenerative Medicine, Universiteitssingel 40, 6229 ER Maastricht, The Netherlands \\ ${ }^{3}$ Institut für Klinische Transfusionsmedizin, Städtisches Klinikum Braunschweig gGmbH, Celler Strasse 38, \\ 38114 Braunschweig, Germany. \\ ${ }^{4}$ Current Address: Department of Vaccinology, Helmholtz Centre for Infection Research, Inhoffenstr. 7, \\ D-38124 Braunschweig, Germany. \\ ${ }^{5}$ Medisch Spectrum Twente, PO Box 50 000, 7500 KA Enschede, The Netherlands \\ ${ }^{6}$ Current Address: Department of Cell Biology-Inspired Tissue Engineering, MERLN Institute for Technology- \\ Inspired Regenerative Medicine, Universiteitssingel 40, 6229 ER Maastricht, The Netherlands
}

\begin{abstract}
The amount of bone generated using current tissue engineering approaches is insufficient for many clinical applications. Previous in vitro studies suggest that culturing cells as 3D aggregates can enhance their osteogenic potential, but the effect on bone formation in vivo is unknown. Here, we use agarose wells to generate uniformly sized mesenchymal stromal cell (MSC) aggregates. When combined with calcium phosphate ceramic particles and a gel prepared from human platelet-rich plasma, we generated a tissue engineered construct that significantly improved in vivo bone forming capacity as compared to the conventional system of using single cells seeded directly on the ceramic surface. Histology demonstrated the reproducibility of this system, which was tested using cells from four different donors. In vitro studies established that MSC aggregation results in an up-regulation of osteogenic transcripts. And finally, the in vivo performance of the constructs was significantly diminished when unaggregated cells were used, indicating that cell aggregation is a potent trigger of in vivo bone formation by MSCs. Cell aggregation could thus be used to improve bone tissue engineering strategies.
\end{abstract}

Keywords: Bone tissue engineering, bone regeneration, calcium phosphate, mesenchymal stem cell.

\footnotetext{
*Address for correspondence:

J. de Boer

Department of Cell Biology-Inspired Tissue Engineering MERLN Institute for Technology-Inspired Regenerative Medicine 6229 ER Maastricht

The Netherlands
}

Telephone: +31 653721953

Email: jan.deboer@maastrichtuniversity.nl

\section{Introduction}

Numerous animal studies and clinical trials have been performed to optimise the use of mesenchymal stromal cells (MSCs) for bone tissue engineering, with both revealing that the degree of bone formation is frequently inadequate (Chatterjea et al., 2010; Griffin et al., 2011; Meijer et al., 2008). One challenge is that while MSCs can be easily isolated from a variety of adult tissues and differentiated into multiple adult cell types including bone cells, their low frequency and limited propensity for osteogenic differentiation often necessitates in vitro expansion and pre-differentiation (Bruder et al., 1998; Friedenstein et al., 1966). Taken together, these limitations establish the importance of developing conditions that can improve both the bone forming capacity of MSCs and reduce the need for in vitro expansion.

Within the developing limb, condensation of MSCs triggers the process of differentiation, favouring chondrogenesis and osteogenesis (Hall and Miyake, 2000). For tissue engineering applications, it is thought that the aggregation of MSCs could initiate that same developmental programme (Achilli et al., 2012; Fennema et al., 2013). MSC aggregation has been shown to improve their differentiation capacity (Wang et al., 2009), particularly as a model for chondrogenic differentiation and cartilage tissue engineering (Ravindran et al., 2011; Steck et al., 2005), and to generate a cartilage template for bone formation (Jukes et al., 2008; Rivron et al., 2012; Scotti et al., 2010). Fewer studies have explored MSC aggregation for osteogenic differentiation. An early study showed that aggregated rat cells had a higher degree of alkaline phosphatase expression, an important bone marker, than those cultured in a monolayer on tissue culture plastic (Gerber and ap Gwynn, 2002). Additional studies have demonstrated the positive effect of MSC aggregation on gene and protein expression related to bone formation in vitro (Kale et al., 2000), but definitive studies revealing an advantage in vivo are lacking.

The present study thus aims to establish the importance of cell aggregation on osteogenic differentiation of MSCs in vitro and in vivo by directly comparing both aggregated and unaggregated MSCs combined with ceramic particles 
and a platelet-rich plasma (PRP) gel. The growth factors from the platelet-rich plasma, which can be used in a clinical setting, have been shown to positively affect the proliferation of MSCs (Lucarelli et al., 2003) and are thought to play a role in their osteogenic differentiation (Intini, 2009). When combined with biomaterials and cells, platelet-rich plasma has also been shown to promote bone formation in heterotopic sites (Bi et al., 2010; Kasten et al., 2008; Yamada et al., 2004). Studies to determine the time required to culture the MSCs as aggregates in order to optimise the amount of bone formed in vivo are performed so as to make the system more clinically feasible. The PRP construct also was compared to a conventional bone tissue engineering construct, in which cells are seeded directly on the ceramic scaffold, to demonstrate the advantage offered by MSC aggregation.

\section{Materials and methods}

\section{Cell culture}

Human mesenchymal stromal cells (MSCs) were either obtained from bone marrow aspirates or commercially (Lonza) as cryopreserved cells. Bone marrow aspirates of 5-20 mL were obtained from healthy donors (male and female, ages 53-72) during hip replacement surgery with written informed consent. Upon isolation, the cells were resuspended using a $20 \mathrm{G}$ needle, and plated at a density of 50,000 mononuclear cells $/ \mathrm{cm}^{2}$. MSCs were expanded in $\alpha$-minimal essential medium ( $\alpha$-MEM, Life Technologies) supplemented with $10 \%(\mathrm{v} / \mathrm{v})$ foetal bovine serum (FBS, Cambrex), $0.2 \mathrm{mM}$ ascorbic acid, $2 \mathrm{mM}$ L-glutamine, $100 \mathrm{U} / \mathrm{mL}$ penicillin, $10 \mu \mathrm{g} / \mathrm{mL}$ streptomycin, and $1 \mathrm{ng} /$ $\mathrm{mL}$ basic fibroblast growth factor (Instruchemie). Cells were cultured at $37{ }^{\circ} \mathrm{C}$ in a humid atmosphere with $5 \%$ $\mathrm{CO}_{2}$. Medium was refreshed twice weekly and prior to confluence, cells were trypsinised and cryopreserved until needed.

\section{Generation of cell aggregates}

MSC aggregates were formed by seeding cells within agarose microwells (Rivron et al., 2012). First, a polydimethylsiloxane (PDMS) stamp of the inverse of 1400 circular wells (each $400 \mu \mathrm{m}$ in diameter and height) was produced from a silicon wafer using standard lithographic techniques (Xia et al., 1996). Following sterilisation in $70 \%$ ethanol, the PDMS stamp was covered with $3 \%(\mathrm{w} / \mathrm{v})$ ultra pure agarose (Invitrogen). Upon solidification, the agarose templates were de-moulded and transferred to a non-adherent 12-well tissue culture plate. After wetting the agarose microwell templates with cell culture medium, 1.5 million cells concentrated in 1 $\mathrm{mL}$ of medium (unless otherwise stated) were uniformly dispersed over the wells. Following a brief centrifugation at $1500 \mathrm{rpm}$ to facilitate entering the wells, the cells were cultured for $24 \mathrm{~h}$ in differentiation medium [Dulbecco's Modified Eagle Medium supplemented with $0.1 \mu \mathrm{M}$ dexamethasone, $50 \mu \mathrm{g} / \mathrm{mL}$ ascorbic acid, $40 \mu \mathrm{g} / \mathrm{mL}$ proline, $100 \mu \mathrm{g} / \mathrm{mL}$ sodium pyruvate, and $50 \mathrm{mg} / \mathrm{mL}$ ITS 1 Premix (Becton-Dickinson)], during which they spontaneously formed aggregates.

\section{Platelet-rich plasma isolation}

To obtain platelets, a standard thrombocyte apheresis procedure was performed on healthy donors using a Cobe Spectra/Trima apheresis unit following written consent. Thereafter, the platelets from a single donor were preserved at $-80{ }^{\circ} \mathrm{C}$. At the time of the experiment, the platelets from several donors were pooled, lysed at $37^{\circ} \mathrm{C}$, and $235 \mu \mathrm{L}$ of $1 \mathrm{M}$ calcium chloride was added per $10 \mathrm{~mL}$ of lysate for $10 \mathrm{~min}$ at $37^{\circ} \mathrm{C}$ on a roller shaker. The resulting solution was separated into a clear liquid (thrombin source) and a gel-like platelet lysate component (fibrinogen source).

\section{Platelet-rich plasma (PRP) constructs}

Platelet-rich plasma (PRP) constructs were prepared by combining the aggregated MSCs and particles of a calcium phosphate ceramic into the PRP gel (Fig. 1a). Biphasic calcium phosphate $(\mathrm{BCP})$ ceramic particles were produced according to the $\mathrm{H}_{2} \mathrm{O}_{2}$ method including naphthalene at a sintering temperature of $1150{ }^{\circ} \mathrm{C}$ for a particle size of 53$63 \mu \mathrm{m}$ (Yuan et al., 2002). MSC aggregates, which had been cultured for $24 \mathrm{~h}$ in the agarose microwells, were flushed from the wells with medium and transferred to a $10 \mathrm{~mL}$ conical tube containing $25 \mathrm{mg}$ of BCP particles. Following a brief centrifugation, $300 \mu \mathrm{L}$ of the prepared thrombin solution was added to the cell aggregate and $\mathrm{BCP}$ particle mixture, followed by $300 \mu \mathrm{L}$ of platelet lysate. The contents of the tube were transferred to a non-adherent 25-well plate that had been pre-warmed to $37^{\circ} \mathrm{C}$, where a PRP gel encapsulated the MSC aggregates and BCP particles in 10-12 s. The PRP constructs were thereafter maintained in differentiation medium at $37^{\circ} \mathrm{C}$ for two weeks prior to implantation, unless indicated otherwise. To isolate the effects of the aggregation of MSCs, 1.5 million unaggregated cells were alternatively added to the BCP particles and incorporated in a PRP gel using the aforementioned strategy (Fig. 1b).

\section{Cell-ceramic constructs}

To compare the PRP construct to a more commonly used tissue engineering approach, cell-ceramic constructs without the PRP gel were prepared (Fig. 1c). A suspension of 600,000 MSCs was seeded on three 1-2 mm BCP particles. For comparison, PRP constructs were also prepared with 600,000 instead of $1.5 \times 10^{6}$ cells. The cellceramic construct was cultured for two weeks in $\alpha$-MEM supplemented with $10 \%(\mathrm{v} / \mathrm{v})$ FBS, $0.2 \mathrm{mM}$ ascorbic

Table 1. Quantitative PCR primer sequences

\begin{tabular}{|l|l|}
\hline Gene & Primers Fwd and $\mathbf{R e v}\left(\mathbf{5}^{\prime}\right.$ to $\mathbf{3}^{\prime}$ ) \\
\hline$B 2 M$ & $\begin{array}{l}\text { GACTTGTCTTTCAGCAAGGA } \\
\text { ACAAAGTCACATGGTTCACA }\end{array}$ \\
\hline ALPL & $\begin{array}{l}\text { GACCCTTGACCCCCACAAT } \\
\text { GCTCGTACTGCATGTCCCCT }\end{array}$ \\
\hline$S P P 1$ & $\begin{array}{l}\text { CCAAGTAAGTCCAACGAAAG } \\
\text { GGTGATGTCCTCGTCTGTA }\end{array}$ \\
\hline$B M P 2$ & Commercially bought (SABiosciences) \\
\hline
\end{tabular}


acid, $2 \mathrm{mM}$ L-glutamine, and $10 \mu \mathrm{M}$ dexamethasone prior to implantation.

\section{Cell quantification}

For cell quantification, constructs were transferred to a tube containing CyQUANT (Molecular Probes) cell lysis buffer and were frozen at $-80^{\circ} \mathrm{C}$. After $24 \mathrm{~h}$, the contents of the tubes were thawed to ambient temperature and sonicated to release the DNA into the supernatant. Total DNA was quantified with a CyQUANT DNA kit on a fluorescence plate reader (Perkin-Elmer Victor 3), and compared to a standard curve.

\section{Gene expression analysis}

After 2 weeks in vitro, constructs were prepared for gene expression analysis. They were washed with PBS, lysed in Trizol reagent (Invitrogen) for $5 \mathrm{~min}$, and stored at $-80^{\circ} \mathrm{C}$ until RNA isolation. RNA was isolated using a NucleoSpin RNA II kit (Machery-Nagel), and was assessed on a NanoDrop 1000. First strand cDNA was synthesised using iScript (BioRad). Real-time qPCR was performed on $1 \mu \mathrm{L}$ cDNA, on a LightCycler (Roche) for a panel of osteogenic genes. Relative gene expression was calculated using the $\Delta \Delta \mathrm{Ct}$ method, with $\mathrm{B} 2 \mathrm{M}$ (beta-2-microglobulin) as a housekeeping gene. Primer sequences are listed in Table 1.

\section{In vivo studies}

All in vivo experiments were approved by the local animal experimental committee. Constructs were implanted ectopically in immunodeficient mice, a widely used model for assessing the bone forming capacity of MSCs (Scott et al., 2012). Ten immune deficient male mice (Hsd-cpb: NMRI-nu, Harlan Laboratories) were used for each of the experiments except in the time course study, when six animals were sacrificed at each of the three time points (2, 4 and 8 weeks). The mice were observed for healthy behaviour following surgery and were anaesthetised by inhalation of isoflurane and carbon dioxide. Four subcutaneous pockets were made on the dorsal aspect of each mouse for implantation (one construct of approximately $6 \mathrm{~mm}$ diameter per pocket), after which the incisions were closed using a vicryl suture. To explant the samples, the mice were sacrificed using carbon monoxide.

\section{Bone histology and quantification}

To quantify bone formation, the explanted samples were fixed in $4 \%(\mathrm{w} / \mathrm{v})$ paraformaldehyde and embedded in methacrylate for sectioning. Sections (approximately $10 \mu \mathrm{m}$-thick) were prepared with a histological diamond saw (Leica microtome), and stained with basic fuchsin and methylene blue to visualise bone formation. The newly formed mineralised bone stained red with basic fuchsin, the unmineralised osteoid stained light pink, other cellular tissues stained light blue with methylene blue, and the ceramic material remained unstained by both dyes. Histological sections were qualitatively analysed by light microscopy (Nikon E600), and scored either positive or negative for bone formation. In addition, quantitative histomorphometry was performed. Briefly, high-resolution digital photographs were made of three sections. The bone and the ceramic material were manually pseudo-coloured using Adobe Photoshop CS2, and a custom-made Matlab a

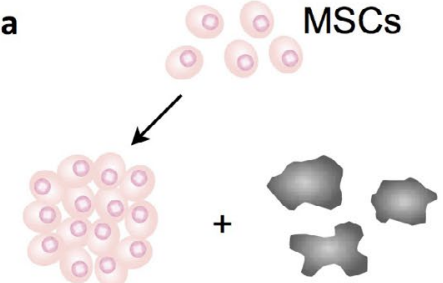

Aggregates Ceramic particles
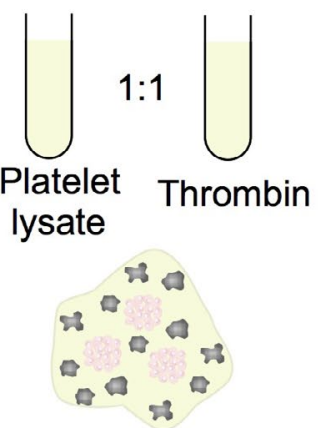

PRP construct b
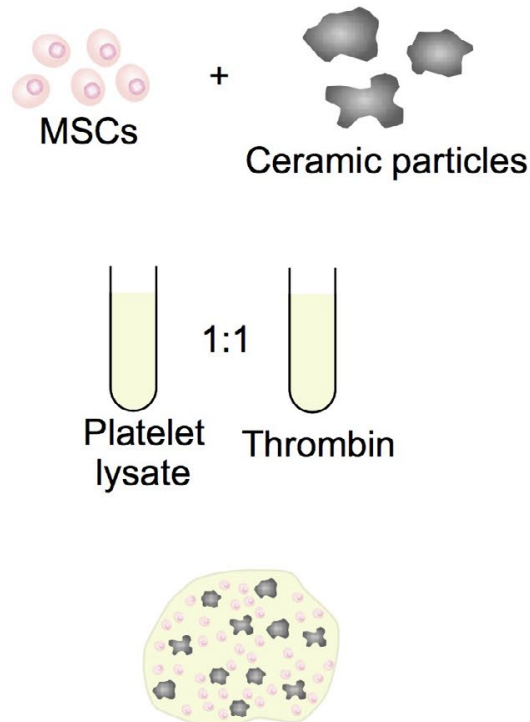

Unaggregated PRP construct c

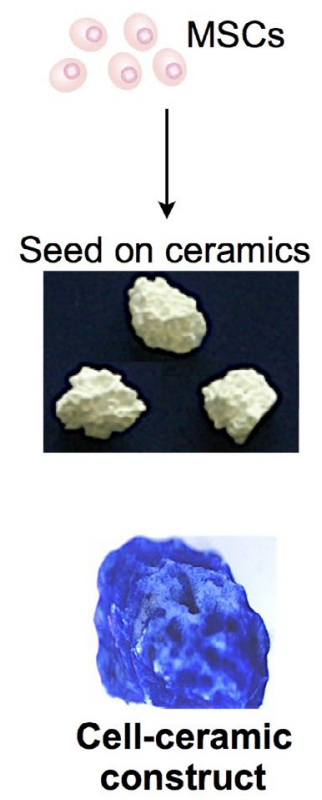

Fig. 1. A schematic of the three experimental groups. (a) To generate the "PRP construct", mesenchymal stromal cells (MSCs) were aggregated, combined with biphasic calcium phosphate (BCP) particles, and then combined with a platelet-rich plasma (PRP) gel prior to implantation.(b) Unaggregated MSCs were incorporated as a control for the effects of cell aggregation, referred to as the "unaggregated PRP construct". (c) A conventional tissue engineering approach in which cells are seeded directly on a scaffold was also used for comparison, referred to as the "cell-ceramic construct". 
(MathWorks) script was used to measure the bone/ceramic surface ratios, which were averaged from three randomly selected, non-continuous sections per sample.

\section{Statistical analysis}

Statistical analysis for the in vivo experiments was performed using ten mice (except in the time course study, where six mice were used per time point) and three sections per implant. For in vitro studies, the experiments were performed in independent triplicates. When differences between two groups were analysed, a Student's $t$-test was used. In studies where three or more groups were compared, results were analysed with one-way analysis of variance (ANOVA) with Tukey's post-hoc analysis. Results were considered statistically significant when $p<0.05$.

\section{Results}

\section{The PRP construct forms bone in vivo}

We first sought to demonstrate that the combination of the PRP gel, ceramic particles, and aggregated cells (the "PRP construct", Fig. 1a) could reproducibly form bone in an ectopic location in immunodeficient mice.
Ten PRP constructs were prepared from each cell source (three different primary donors and one commercial cell source). After six weeks of implantation, bone formation was observed in all constructs, with an average of $20.1 \%$ of the total scaffold area filled with bone (Fig. 2a). In all constructs, there were areas of mature bone aligning areas of osteoid (Fig. 2b), and regions suggestive of bone marrow, indicating a functional bone organ (Fig. 2b-d). No signs of inflammation were observed.

\section{MSCs are necessary for bone formation}

It was then important to determine whether the implanted cells were, in fact, necessary for bone formation. Since the PRP gel is a storehouse for multiple growth factors (Landi et al., 2011; Yang et al., 2011), many of which are involved in bone formation, and the ceramics alone can induce bone formation in ectopic sites (Carragee et al., 2011), we considered that the PRP construct may be capable of recruiting cells to form bone. To test this, we compared bone formation in the PRP construct implanted both with and without cells. Following 2 weeks of culture in vitro of the constructs with cells, both types of constructs were implanted subcutaneously in ten mice. While abundant bone (average of $11.2 \%$ bone/scaffold area) was observed
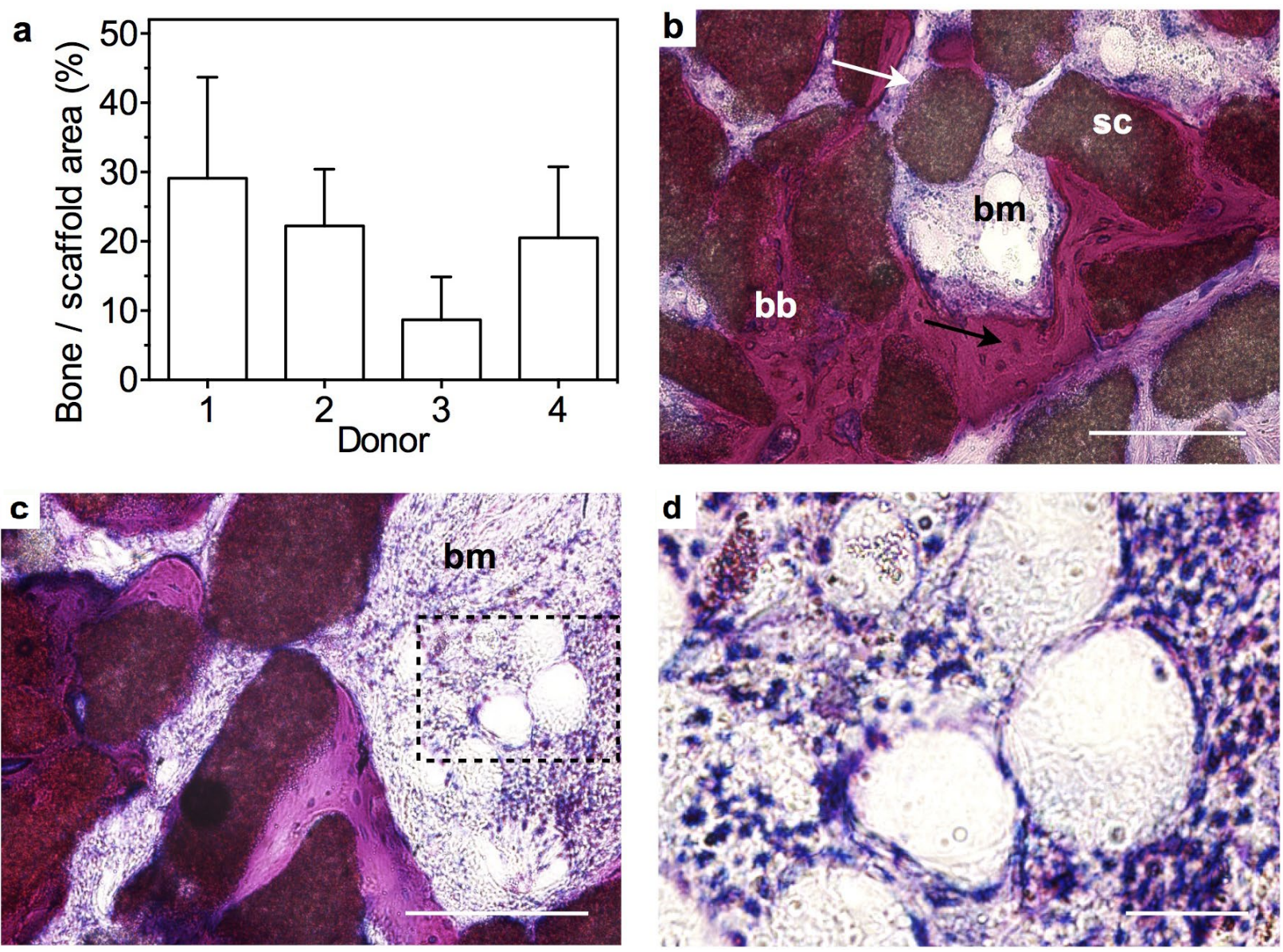

Fig. 2. The PRP construct forms bone upon implantation. (a) With MSCs derived from three patients (donors 1-3) and one commercial source (donor 4), bone was detected after six weeks in vivo. (b) With cells from all donors, there were large areas of mature bone (bb), embedded osteocytes (black arrow), and osteoblasts (white arrow). Areas of bone marrow (bm) were also observed, which is shown in more detail in (c) and at a higher magnification of the boxed region in (d). Scale bars in $\mathbf{b}, \mathbf{c}: 100 \mu \mathrm{m}, \mathbf{d}: 20 \mu \mathrm{m} . n=10$. 
in the cell-laden PRP construct, no evidence of bone was observed in the constructs lacking cells (Fig. 3a, quantified in Fig. 3b).

\section{The PRP gel is superior to cells seeded directly on scaffolds}

Next, to establish the role of the PRP gel, we compared the PRP construct to a conventional tissue engineering construct, in which MSCs are seeded directly on a ceramic (the "cell-ceramic construct", Fig. 1c). Ten of each construct were prepared with 600,000 cells from each of two donors. For the PRP construct, they were aggregated according to the above method, while in the conventional construct, cells were carefully seeded directly on the ceramic particles. After two weeks of in vitro culture, cell number was quantified. There were significantly more cells on the scaffolds in the conventional construct than the PRP construct after the 2 week culture period (Fig. 4a). The constructs were then implanted in ten mice for 6 weeks, after which they were explanted and bone formation was quantified. The amount of bone formed was significantly greater in the PRP construct compared to the cell-ceramic construct (Fig. 4b), increasing from $5.0 \%$ to $22.0 \%$ with cells from one donor and $0 \%$ to $8.6 \%$ from another.

\section{Cell aggregation increases the amount of bone formed}

We then sought to establish the role of cell aggregation in the PRP construct by implanting constructs with either aggregated or unaggregated cells $(n=10$ mice). After six weeks of implantation, histological examination of bone formation (for a mineralised matrix with embedded osteocytes) revealed that both constructs initiated the formation of bone tissue, but the amount was significantly
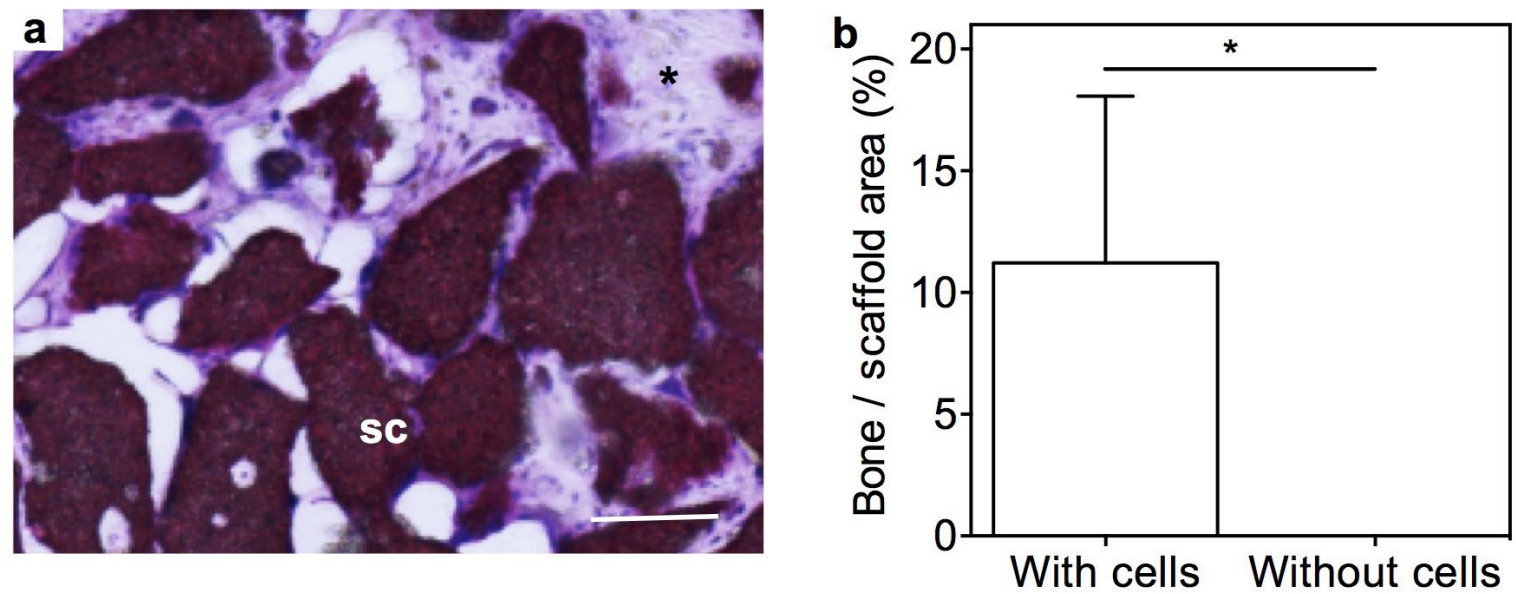

Fig. 3. MSCs need to be implanted for bone formation. (a) When the PRP gel was implanted without cells, only the scaffold (sc) could be viewed, and no bone formation was detected. The difference in bone formation when constructs were implanted both with and without cells is quantified in (b). Scale: $100 \mu \mathrm{m} . n=10$.

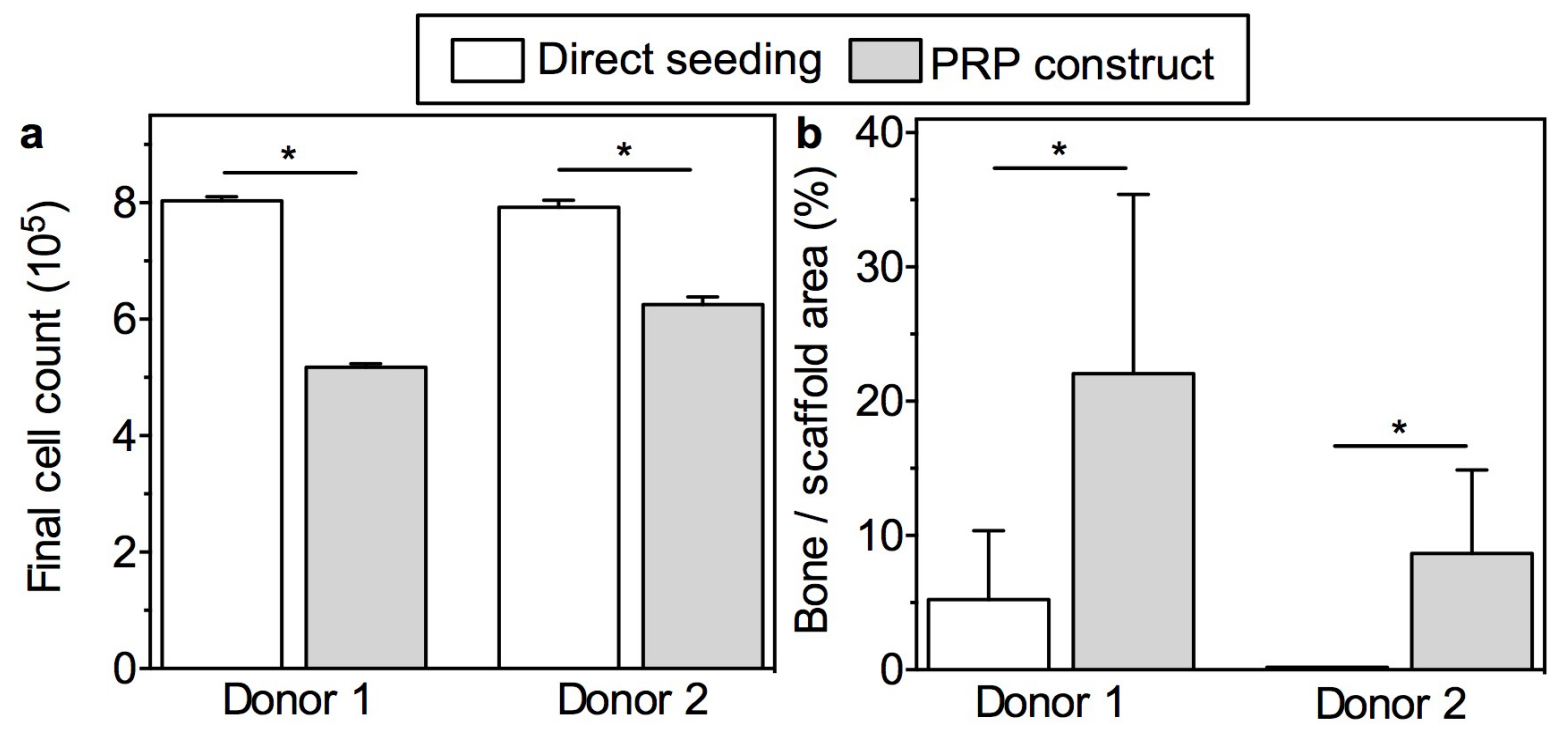

Fig. 4. Implanting cells in the PRP construct is superior to seeding them directly on a ceramic. (a) After 2 weeks in vitro, the total number of cells was significantly diminished within the PRP construct compared to on ceramic scaffolds. (b) However, after six weeks of implantation, there was significantly more bone formation when the PRP construct was implanted compared to when cells were directly seeded on scaffolds. ${ }^{*}$ signifies $p<0.05 . n=10$. 
higher when MSC aggregates were used (Fig. 5a). Specifically, the total amount of bone formed increased from $5.3 \%$ to $29.1 \%$ with cells from one donor, and from $7.6 \%$ to $22.2 \%$ with cells from a second donor in constructs with the same number of unaggregated and aggregated cells, respectively. This effect could not be attributed to differential rates of cell proliferation in the different constructs, since after two weeks of culture in vitro $\left(\mathrm{n}=10\right.$ constructs with $1.5 \times 10^{6}$ cells $)$, a cell quantification assay revealed no statistically significant difference in cell number (Fig. 5b). It is unlikely that the large difference in bone formation came from a small difference in cell number.

\section{Cell aggregation improves the expression of bone markers}

We were also interested to see if cell aggregation could enhance the in vitro expression of genes related to osteogenic differentiation. We performed qPCR after 2 weeks in vitro and found that the osteogenic genes were generally up-regulated in aggregated cells compared to unaggregated (Fig. 5c,d). ALPL (alkaline phosphatase) and $B M P 2$ (bone morphogenetic protein-2) expression were up-regulated $(p<0.05)$ in aggregated cells from both donors, and SPP1 (osteopontin) was up-regulated in aggregated cells from one donor.

\section{In vitro culture time is insignificant}

A limitation to the clinical usefulness of tissue engineering constructs is the prolonged in vitro culture time prior to implantation. We therefore sought to test whether our system could induce bone formation even after a shortened incubation period in vitro. Ten PRP constructs were cultured in differentiation medium for 0 (i.e. implanted immediately), 1, 2 or 4 weeks prior to implantation. Following 6 weeks of in vivo implantation, the constructs were explanted and histological analysis was performed. The results indicated that bone formed irrespective of the in vitro culture time (Fig. 6a). The average amount of bone occupying the total scaffold area was $10.4 \%, 16.7 \%$, $20.5 \%$, and $8.0 \%$ for constructs cultured for $0,1,2$ or 4 weeks, respectively (one-way ANOVA, $p>0.05$ ).

\section{Mature bone begins to form after four weeks}

Finally, to obtain information on the time-course of bone formation, we generated PRP constructs using aggregated cells from two donors, implanted them in nude mice, and explanted samples after 2, 4 and 8 weeks for histology.
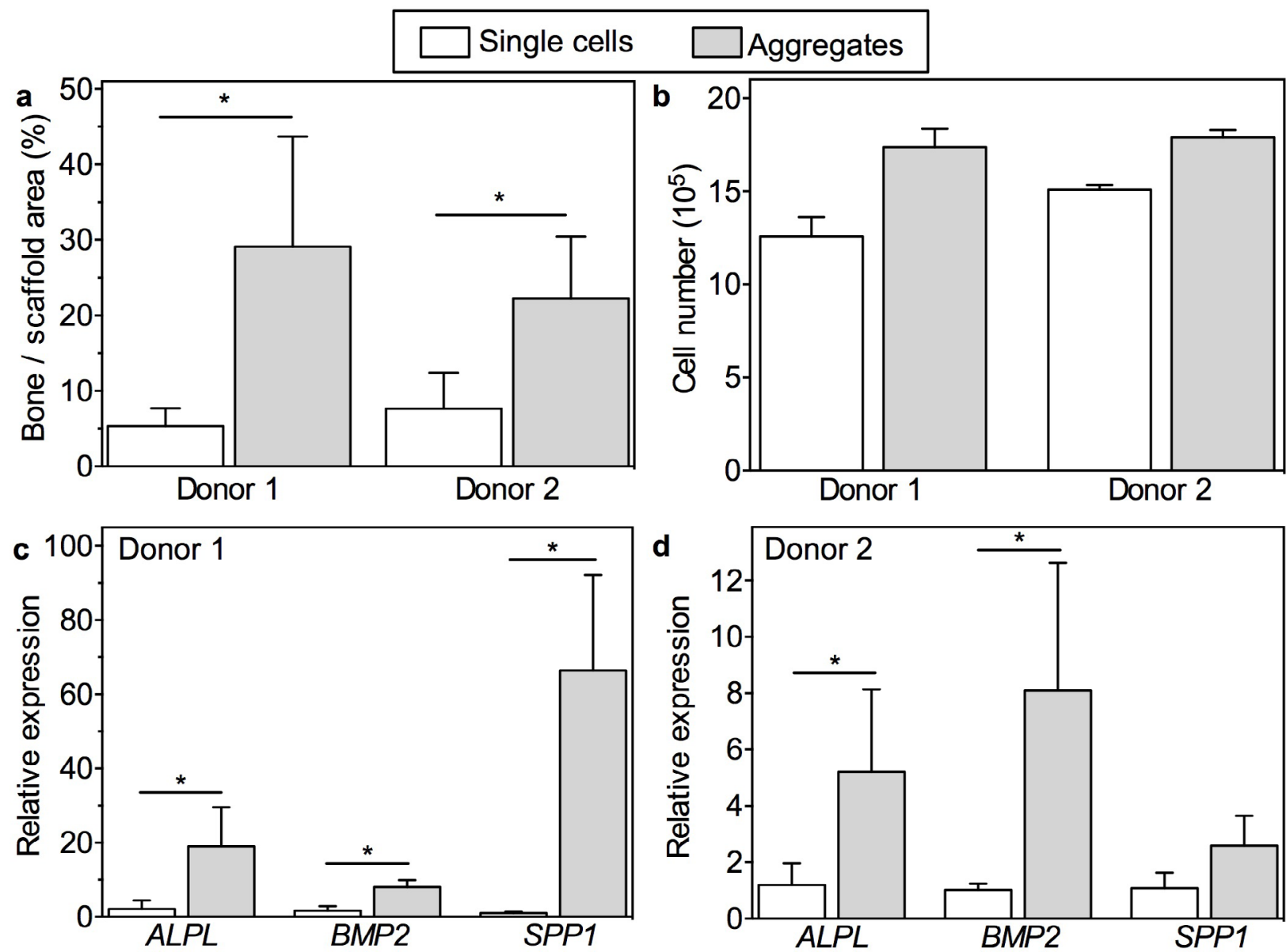

Fig. 5. Cell aggregation enhances bone formation in the PRP construct. (a) When compared to a PRP construct with unaggregated MSCs (white bars), those with aggregated cells (grey bars) formed significantly more bone after 6 weeks in vivo $(n=10)$. (b) This could not be attributed to cell number, since there were non-significant $(p>0.1)$ differences between the two groups. $(\mathbf{c}, \mathbf{d})$ In cells from two donors, qPCR revealed an up-regulation of the osteogenic genes $A L P L, B M P 2$, and SPP1 $(n=3)$. 

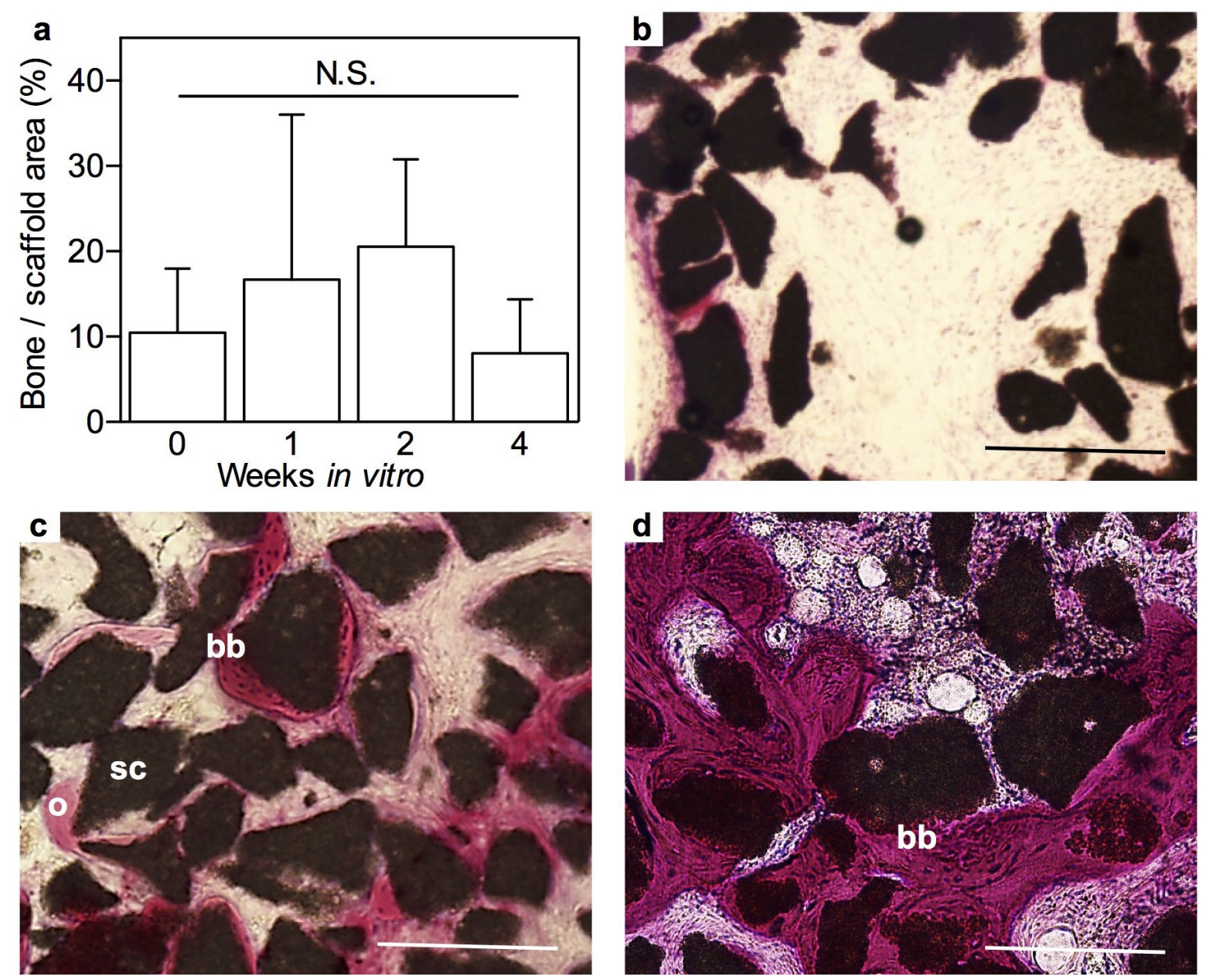

Fig. 6. Bone formation occurs over a period of eight weeks in vivo. (a) The in vitro pre-differentiation time had no significant bearing on bone formation following six weeks of implantation $(n=10)$. (b) After two weeks of implantation, methylene blue and basic fuchsin staining revealed no bone formation in the cell-ceramic construct. (c) After 4 weeks, some bone (bb) around the ceramic scaffolds (sc) was observed, as well as osteoid (o). (d) Between four and eight weeks, mature bone and bone marrow formed $(n=6)$. Scales: $100 \mu \mathrm{m}$.

After 2 weeks, we found no evidence of cartilage or mature bone although very small areas reminiscent of osteoid were observed (Fig. 6b). Four weeks after implantation, there were areas of mature bone lined with areas of osteoid tissue (Fig. 6c). After 8 weeks, the amount of mature bone as well as osteoid tissue was further increased (Fig. 6d) and areas suggestive of bone marrow were also observed.

\section{Discussion}

The clinical application of MSCs in the field of bone tissue engineering is partly impaired by the suboptimal amount of bone generated using conventional methods and the variation in the ability of the isolated cells to form bone in vivo (Siddappa et al., 2007). In this study, we describe a clinically applicable in vitro culture system that, by the simple step of cell aggregation and incorporation in a platelet-rich plasma (PRP) gel with calcium phosphate particles, programmes donor-derived MSCs to reproducibly generate significantly greater amounts of bone than that obtained by a conventional bone tissue engineering approach in which a cell suspension is seeded on the scaffold. The efficacy of this approach was exemplified when cells from one donor led to $8 \%$ of the total scaffold area filled with bone, while they failed to generate any detectable bone with the conventional system.

Cell aggregation was demonstrated to be responsible for some of the positive effects of the PRP construct, and represents a strategy to enhance the bone formation capacity of the limited number of MSCs that can be derived from bone marrow. We show that in vitro aggregation is a simple, safe and cost-effective step that thereafter improves the performance of the cells upon implantation in vivo. The beneficial effects were in accordance with the enhanced in vitro expression of osteogenic genes observed in this study, as well as that reported in a number of recent publications (Baraniak and McDevitt, 2012; Frith et al., 2010; Ma et al., 2011). Cell aggregation is also commonly used for chondrogenic differentiation (Erickson et al., 2002; Puetzer et al., 2010; Wang et al., 2003), in other disciplines such as cancer research, and in the pharmaceutical industry in 
order to test the potential in vivo effects of drug therapies (Kobayashi et al., 1993; Kunz-Schughart, 2004), but this study establishes its potential for bone tissue engineering.

Another significant advantage of the approach described in this study is that the in vitro culture time of the constructs had no statistically significant effect on the amount of bone formation after six weeks of implantation. This is an improvement upon a previously reported strategy, where cell aggregates without ceramics were first matured into cartilage templates in vitro before implantation to generate bone in vivo (Scotti et al., 2010). In that study, at least two weeks of in vitro maturation were required to ensure their retrieval at the time of explantation, a time-frame that could be unsuitable for clinical applications. In contrast, the PRP constructs in this study could be filled with a large amount of bone, even without an in vitro maturation step.

The primary cells isolated from human donors did not show any evidence of cartilage tissue, suggesting bone formed via the intramembranous ossification route. One possible explanation is that it is well known that bone formation can be modulated by environmental factors such as growth factors, oxygen concentration, or mechanical stimuli (Gawlitta et al., 2010) and, in this experiment, the cells were isolated at ambient oxygen, which has been shown to diminish their chondrogenic potential (Morita et al., 2007). It is also likely that yet unidentified factors present both in vitro and in vivo can influence the behaviour of cells and determine the path taken by them to generate bone.

It is a reasonable reality that tissue engineered constructs containing MSCs will be available in the clinic in the near future. The optimisation of methods to isolate cells and prepare a scaffold that can reliably induce bone formation is therefore of high interest and importance. In this study, we show that patient-derived MSCs can be combined with a PRP gel derived from human plasma and calcium phosphate ceramics, and that this will form bone without the need for recombinant proteins such as growth factors, or other biomolecules. The success of the approach could be attributed to the pre-aggregation of the MSCs, a simple method that led to strikingly higher bone formation in vivo. The PRP gel itself is also an especially strong candidate for tissue engineering because it is patient-derived, chemical-free, a source of a plethora of growth factors, and can gel at a physiological temperature. Indeed, we recently demonstrated that it could be injected and gelled in situ (Chatterjea et al., 2013), and this work shows its promise for implantable bone tissue engineering.

\section{Conclusions}

The clinical efficacy of bone tissue engineering is limited by the insufficient quantity of bone produced. By preaggregating human mesenchymal stromal cells prior to combining them with calcium phosphate ceramics and a platelet-rich plasma gel, we were able to reproducibly generate more bone tissue in nude mice and more bone markers in vitro. The aggregation was central to enhanced bone formation, and we found that the in vitro maturation period typically required prior to implantation could be eliminated. In conclusion, this study underlines the notion that MSC aggregation is a potent trigger of in vivo bone formation, a finding that could improve bone tissue engineering approaches.

\section{Acknowledgements}

The authors gratefully acknowledge the support of the TeRM Smart Mix Program of The Netherlands Ministry of Economic Affairs and The Netherlands Ministry of Education, Culture and Science. Project number S-14-29L was supported by the AO Foundation.

\section{References}

Achilli T-M, Meyer J, Morgan JR (2012) Advances in the formation, use and understanding of multi-cellular spheroids. Expert Opin Biol Ther 12: 1347-1360.

Baraniak PR, McDevitt TC (2012) Scaffold-free culture of mesenchymal stem cell spheroids in suspension preserves multilineage potential. Cell Tissue Res 347: 701711.

Bi L, Cheng W, Fan H, Pei G (2010) Reconstruction of goat tibial defects using an injectable tricalcium phosphate/ chitosan in combination with autologous platelet-rich plasma. Biomaterials 31: 3201-3211.

Bruder SP, Kurth AA, Shea M, Hayes WC, Jaiswal N, Kadiyala S (1998) Bone regeneration by implantation of purified, culture-expanded human mesenchymal stem cells. J Orthop Res 16: 155-162.

Carragee EJ, Hurwitz EL, Weiner BK (2011) A critical review of recombinant human bone morphogenetic protein-2 trials in spinal surgery: emerging safety concerns and lessons learned. Spine J 11: 471-491.

Chatterjea A, Meijer G, van Blitterswijk C, de Boer J (2010) Clinical application of human mesenchymal stromal cells for bone tissue engineering. Stem Cells Int: 215625.

Chatterjea A, Yuan H, Chatterjea S, Garritsen H, Renard A, van Blitterswijk CA, de Boer J (2013) Engineering new bone via a minimally invasive route using human bone marrow-derived stromal cell aggregates, microceramic particles, and human platelet-rich plasma gel. Tissue Eng Part A 19: 340-349.

Erickson GR, Gimble JM, Franklin DM, Rice HE, Awad H, Guilak F (2002) Chondrogenic potential of adipose tissue-derived stromal cells in vitro and in vivo. Biochem Biophys Res Commun 290: 763-769.

Fennema E, Rivron N, Rouwkema J, van Blitterswijk C, de Boer J (2013) Spheroid culture as a tool for creating 3D complex tissues. Trends Biotechnol 31: 108-115.

Friedenstein AJ, Piatetzky-Shapiro II, Petrakova KV (1966) Osteogenesis in transplants of bone marrow cells. J Embryol Exp Morphol 16: 381-390.

Frith JE, Thomson B, Genever PG (2010) Dynamic three-dimensional culture methods enhance mesenchymal stem cell properties and increase therapeutic potential. Tissue Eng Part C 16: 735-749.

Gawlitta D, Farrell E, Malda J, Creemers LB, Alblas J, Dhert WJA (2010) Modulating endochondral ossification 
of multipotent stromal cells for bone regeneration. Tissue Eng Part B 16: 385-395.

Gerber I, ap Gwynn I (2002) Differentiation of rat osteoblast-like cells in monolayer and micromass cultures. Eur Cells Mater 3: 19-30.

Griffin M, Iqbal SA, Bayat A (2011) Exploring the application of mesenchymal stem cells in bone repair and regeneration. J Bone Joint Surg Br 93: 427-434.

Hall BK, Miyake T (2000) All for one and one for all: condensations and the initiation of skeletal development. BioEssays 22: 138-147.

Intini $\mathrm{G}$ (2009) The use of platelet-rich plasma in bone reconstruction therapy. Biomaterials 30: 4956-4966.

Jukes JM, Both SK, Leusink A, Sterk LMT, van Blitterswijk CA, de Boer J (2008) Endochondral bone tissue engineering using embryonic stem cells. Proc Natl Acad Sci U S A 105: 6840-6845.

Kale S, Biermann S, Edwards C, Tarnowski C, Morris M, Long MW (2000) Three-dimensional cellular development is essential for ex vivo formation of human bone. Nature Biotechnol 18: 954-958.

Kasten P, Vogel J, Geiger F, Niemeyer P, Luginbühl R, Szalay K (2008) The effect of platelet-rich plasma on healing in critical-size long-bone defects. Biomaterials 29: 3983-3992.

Kobayashi H, Man S, Graham CH, Kapitain SJ, Teicher BA, Kerbel RS (1993) Acquired multicellular-mediated resistance to alkylating agents in cancer. Proc Natl Acad Sci U S A 90: 3294-3298.

Kunz-Schughart LA, Freyer JP, Hofstaedter F, Ebner $\mathrm{R}$ (2004) The use of 3-D cultures for high-throughput screening: the multicellular spheroid model. J Biomol Screen 9: 273-285.

Landi A, Tarantino R, Marotta N, Ruggeri AG, Domenicucci M, Giudice L, Martini S, Rastelli M, Ferrazza G, De Luca N, Tomei G, Delfini R (2011) The use of platelet gel in postero-lateral fusion: preliminary results in a series of 14 cases. Eur Spine J 20: S61-67.

Lucarelli E, Beccheroni A, Donati D, Sangiorgi L (2003) Platelet-derived growth factors enhance proliferation of human stromal stem cells. Biomaterials 24: 3095-3100.

Ma D, Zhong C, Yao H, Liu Y, Chen F, Li J, Zhao J, Mao T, Ren L (2011) Engineering injectable bone using bone marrow stromal cell aggregates. Stem Cells Dev 20: 989-999.

Meijer GJ, de Bruijn JD, Koole R, van Blitterswijk CA (2008) Cell based bone tissue engineering in jaw defects. Biomaterials 29: 3053-3061.

Morita K, Miyamoto T, Fujita N, Kubota Y, Ito K, Takubo K, Miyamoto K, Ninomiya K, Suzuki T, Iwasaki R, Yagi M, Takaishi H, Toyama Y, Suda T (2007) Reactive oxygen species induce chondrocyte hypertrophy in endochondral ossification. J Exp Med 204: 1613-1623.

Puetzer JL, Petitte JN, Loboa EG (2010) Comparative review of growth factors for induction of three-dimensional in vitro chondrogenesis in human mesenchymal stem cells isolated from bone marrow and adipose tissue. Tissue Eng Part B 16: 435-444.

Ravindran S, Roam JL, Nguyen PK, Hering TM, Elbert DL, McAlinden A (2011) Changes of chondrocyte expression profiles in human MSC aggregates in the presence of PEG microspheres and TGF- $\beta 3$. Biomaterials 32: 8436-8445.

Rivron NC, Raiss CC, Liu J, Nandakumar A, Sticht C, Gretz N, Truckenmüller R, Rouwkema J, van Blitterswijk CA (2012) Sonic Hedgehog-activated engineered blood vessels enhance bone tissue formation. Proc Natl Acad Sci U S A 109: 4413-4418.

Scott MA, Levi B, Askarinam A, Nguyen A, Rackohn T, Ting K, Soo C, James AW (2012) Brief review of models of ectopic bone formation. Stem Cells Dev 21: 655-667.

Scotti C, Tonnarelli B, Papadimitropoulos A, Scherberich A, Schaeren S, Schauerte A, Lopez-Rios J, Zeller R, Barbero A, Martin I (2010) Recapitulation of endochondral bone formation using human adult mesenchymal stem cells as a paradigm for developmental engineering. Proc Natl Acad Sci U S A 107: 7251-7256.

Siddappa R, Licht R, van Blitterswijk C, de Boer J (2007) Donor variation and loss of multipotency during in vitro expansion of human mesenchymal stem cells for bone tissue engineering. J Orthop Res 25: 1029-1041.

Steck E, Bertram H, Abel R, Chen B, Winter A, Richter W (2005) Induction of Intervertebral Disc-Like Cells From Adult Mesenchymal Stem Cells. Stem Cells 23: 403-411.

Wang W-G, Lou S-Q, Ju X-D, Xia K, Xia J-H (2003) In vitro chondrogenesis of human bone marrow-derived mesenchymal progenitor cells in monolayer culture: activation by transfection with TGF-beta2. Tissue Cell 35: 69-77.

Wang W, Itaka K, Ohba S, Nishiyama N, Chung U-I, Yamasaki Y, Kataoka K (2009) 3D spheroid culture system on micropatterned substrates for improved differentiation efficiency of multipotent mesenchymal stem cells. Biomaterials 30: 2705-2715.

Xia Y, Kim E, Zhao X, Rogers J, Prentiss M, Whitesides G (1996) Complex optical surfaces formed by replica molding against elastomeric masters. Science 273: 347349.

Yamada Y, Ueda M, Naiki T, Takahashi M (2004) Autogenous injectable bone for regeneration with mesenchymal stem cells and platelet-rich plasma: tissueengineered bone regeneration. Tissue Eng 10: 955-964.

Yang HS, Shin J, Bhang SH, Shin JY, Park J, Im GI, Kim CS, Kim B-S (2011) Enhanced skin wound healing by a sustained release of growth factors contained in plateletrich plasma. Exp Mol Med 43: 622-629.

Yuan H, Van Den Doel M, Li S, van Blitterswijk CA, De Groot K, De Bruijn JD (2002) A comparison of the osteoinductive potential of two calcium phosphate ceramics implanted intramuscularly in goats. J Mater Sci Mater Med 13: 1271-1275.

Editor's note: There were no questions from reviewers for this paper, therefore there is no discussion with reviewers section.

Editor's note: The Scientific Editor responsible for this paper was Martin Stoddart. 